\title{
Effect of Ambient Temperature Variations on Particle Dimesions in Ultrasonic Nebulizers during Cold Vaporization
}

\author{
Ali Akpek* \\ Department of Bioengineering, Gebze Technical University, 44100, Turkey
}

\begin{tabular}{l} 
A R T I C L E I N F O \\
\hline Article history: \\
Received: 30 April, 2017 \\
Accepted: 11 June, 2017 \\
Online: 30 June, 2017
\end{tabular}

Keywords:

Ultrasonic nebulizer

Particle dimension

Cold vaporization

\begin{abstract}
A B S T R A C T
For human comfort and convenience, appropriate temperature values may not be sufficient enough for the environment that they live in. The moisture content of the air has an important place in this regard. $30 \%$ to $65 \%$ humidity is desireable for a relaxed and comfortable life. Humidity in the environment is fundamental for the human health, convenience and comfort. Humidity is also valid for therapeutics. The drugs that are used in medicine for diagnosis and therapy must be inhaled with cold or hot water vapor in case drug effectiveness is desired to be increased. For such achievments, cold vaporization method is being preferred to reach the alveoli of the patients, thus, the drug can be used in a more efficient manner without damaging the respiratory tract. In this project, effect of ambient temperaure in ultrasonic nebulizers is investigated. It is proved that as the temperature increases $5^{\circ} \mathrm{C}$, the speed of cold vapor increases $10 \%$ which refers a decrease in particle diameter. The variations in particle dimension may severely effect the efficiency of therapeutics. Therefore, in this study, it is presented that ultrasonic nebulizers should be designed considering ambient temperature. A design rationale is proposed in this study.
\end{abstract}

\section{Introduction}

For the human comfort and convenience, only appropriate temperature values may not be sufficient for the environment that they live in. The moisture content of the air has an important place in this regard [2]. For a relaxed and comfortable life relative humidity is desirable in the range of $\% 30$ to $\% 65$ in the environment [3]. Humidity in the environment is fundamental for the human health, convenience and comfort [4]. The drugs that used in medicine for diagnosis and therapy must be inhaled with both cold and hot water vapor steam in the patient's body [5]. Cold vaporization method is being preferred to reach the alveoli of the patient, thus, the drug can be used in a more efficient manner without damaging the respiratory tract [6].

Ultrasonic nebulizers utilize water to carry out drugs to the alveols. Ultrasonic nebulizers dissociate water into their smallest particles by sound waves and thus compose cold vapour. Obtained cold vapour and drugs are mixed intoeach other and blown to

${ }^{*}$ Corresponding Author: Ali Akpek, Department of Bioengineering, Gebze

Technical University, 44100, Turkey | Email: aliakpek@mit.edu patient through a mask or directly to the environment. Therefore, respiratory tract is moisturized and the desired drugs are carried out to the alveols of the patients efficiently [7].

Some environments may contain excessive moisture while some of them are over dried. This situation is pretty much common especially among the houses with a radiator during winters and houses with air conditioning in summers. Ideal moisture ratio should be between $30 \%$ and $65 \%$ for human beings. For humans especially for babies, dry air may cause enfections to spread faster, dehydrate pharyngonasal area, burning in the eyes and cracking in the lips. Dust formation becomes rapid and affects those with allergies. [8]. The spread of cold vapor provides accurate humidity in the environment and creates beneficial effects on health. Water droplets have ionizing effect for the air. Negative ions attack pollutant particles in the air, reducing it to a minimum, thereby reducing cigarette smoke, pollens and dust [9]. Medical studies have proved that negative ions have a positive effect on people's physical and psychological health with both their stress-relief functions and their direct effects on respiratory devices which makes them much more effective [10]. 


\section{A. Akpek / Advances in Science, Technology and Engineering Systems Journal Vol. 2, No. 3, 946-950 (2017)}

Simply a nebulizer generates vapour. There are various ways to generate vapour [11]. The most convenient method for this is by heating the liquid. On the other hand an ultrasonic nebulizer system evaporates liquids with ultrasonic sound waves. The major problem here is not evaporating water but obtaining cold vapour.

An ultrasonic nebulizer uses a vibrating piezoelectric crystal that vibrates with $1.7 \mathrm{MHz}$ or higher frequency in order to generate vapour [12]. The crystal transducer is made of materials like quartz-barium titanate and converts electrical signals into sound waves. The sound beam that focuses on the liquid which is located just above the transducer creates waves. When the frequency and amplitude are strong enough, the wave peak reaches the surface of the fluid as a sprinkler of water particles. Working principle of an ultrasonic nebulizer is illustrated in Fig. 1.

Ultrasonic nebulizers are most frequently used in intensive care units. In these units, ultrasonic nebulizers are mainly used for the humidification of the rooms, and also for the evaporation of liquid medicines to assist them to effectively inhaled by respiratory organs. In addition, it is also used to humidify the air for patients who are connected to artificial respiration and oxygen support systems [13].

By the help of this study, effect of ambient temperature on ultrasonic nebulizers is investigated. In order to achieve this, ambient temperature is constantly recorded and particle dimensions of cold vapour are measured. As a result it is understood that, ambient temperature has a serious impact on particle dimension thus affecting the effectiveness of ultrasonic nebulizers therapeutic capability.

In addition, this study aims to further development of national fabrication of ultrasonic nebulizers in Turkey and creates difference in the area of biomedical device fabrication that may not be evaluated as strong [14-22].

\section{Materials and Method}

Ultrasonic nebulizers are based on the princible that disassociating water into its particles with high frequency sound waves that is generated by a vibrating piezoelectric crystal. This piezoelectric crystal that is located under the liquid, generate sound waves with a frequency of $1.7 \mathrm{MHz}$ or more, and disassociating water into its particles.

It is possible to change the particle diameter of of the evaporation by changing the frequency of the piezoelectric crystal. As the frequency of the piezoelectric crystal increases, the particle diameter decreases. As the frequency decreases, the particle diameter increases. As the particle diameter increases, it will be unable for medications or humid air to reach the extreme edges of the alveoli. Same phenomenon is observed when the ambient temperature changes. Particle size decreases as the ambient temperature increases, while particle sizes increase as the ambient temperature decreases.

The quantity of the liquid is important since the piezoelectric crystal is operated inside the liquid. It is important because crystal may deteriorate due to the heat energy that occurs during the formation of the sound waves. For this reason, the quantity of the water is constantly measured and a system is designed that prevents the degradation of the crystal by cutting the energy when there is not enough water left within the device.
Block diagram of the designed ultrasonic nebülizer is illustrated in Fig. 2. A picture of the ultrasonic crystal is presented in Fig. 3. In addition, a level sensor for water measurement is shown in Fig 5.

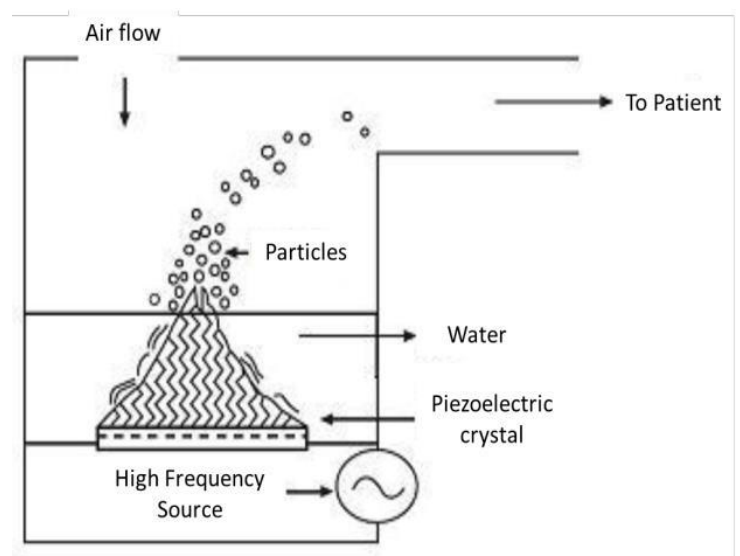

Fig. 1: Working principle of an ultrasonic nebülizer

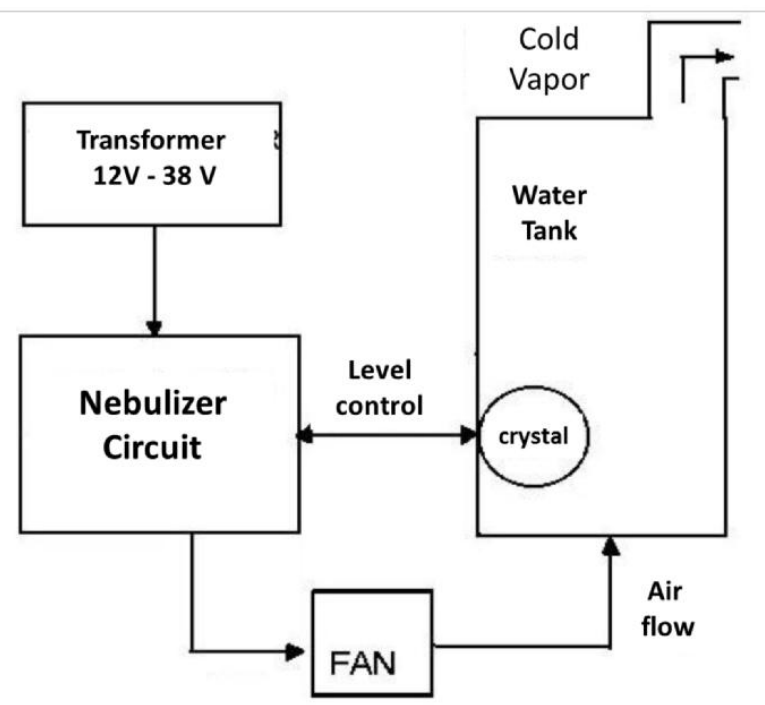

Fig. 2: Block diagram of the designed ultrasonic nebülizer

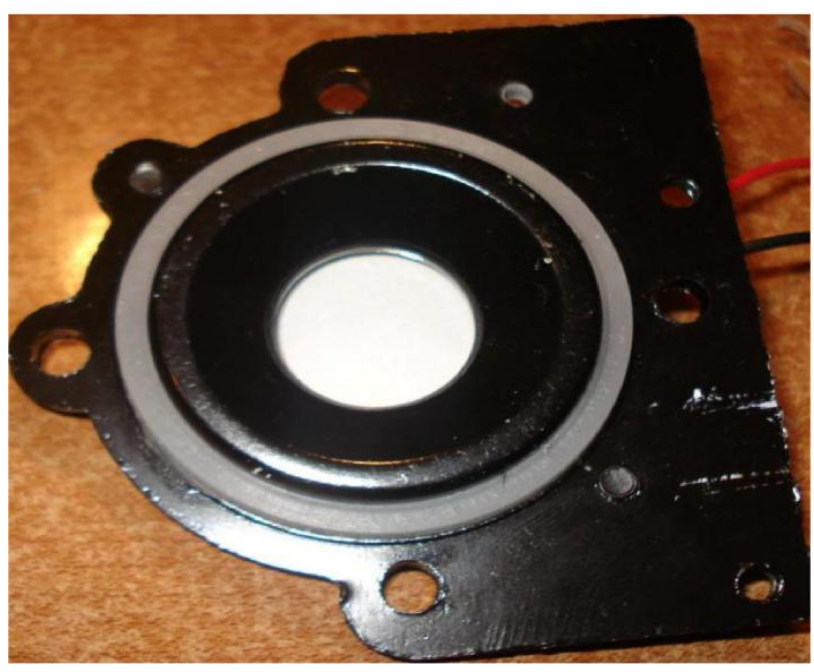

Fig. 3: Ultrasonic crystal 
The design and drawing stages of the nebulizer circuit were first completed using the Proteus ISIS program. The design is simulated with the Proteus ISIS program to check the operability of the system. After being confident that the simulation process of the design is completed and the design may work flawlessly, the process of printing circuit board with Proteus ARES program is started. This process is presented in Fig. 6.

The design of the boxing process has initiated after the control of the nebulizer circuit and date/clock circuit are implemented and operability of the design is controled. Therefore the circuit and system could be used in maximum confort.

A crystal with a special casting design is placed in the lower part of the water tank. BU 406 power transistor that controls the ultrasonic crystal generates a lot of heat due to the high voltage and fast triggering characteristics. Since this heat may damage the transistor, the special casting that surrounds the crystal is used as a cooler. The water within the water tank cools down the casting and casting cools the crystal and the transistor. This is the reason why water level is critically important for this research. The cold vapor that is generated by the crystal is delivered to the patient by the help of a channel just located on the top of the ultrasonic nebulizer.

Finally, chassis is placed and LCD screen that displays ambient temperature, date/time and control parameters is located on it. Therefore the prototype is finalized. LCD screen and the final design of the ultrasonic nebulizer are shown in

\section{Figs. 7,8 and 9.}

The experiments are done by changing the ambient temperatures by several radiators that surrounds the ultrasonic nebulizer. At the beginnig the temperature is recorded as $25^{\circ} \mathrm{C}$ $\pm 0.3^{\circ} \mathrm{C}$. The process is initiated and the period until the visually detection of cold vapor out from the funnel of the nebulizer is recorded. This period provides the speed of the particles of cold vapor thus giving us the estimations for particle dimensions.

As second step the temperature is increased $5^{\circ} \mathrm{C}$ to $30^{\circ} \mathrm{C} \pm$ $0.3^{\circ} \mathrm{C}$, the process is initiated and the period of visually detection of cold vapour is recorded. As third step the temperature is increased to $35^{\circ} \mathrm{C}$ and the entire process is recorded again. As fourth and fifth step, the temperature is reduced to $20^{\circ} \mathrm{C} \pm 0.3^{\circ} \mathrm{C}$ and $15^{\circ} \mathrm{C} \pm 0.3^{\circ} \mathrm{C}$, respectively. In those steps, period of visually detection of cold vapor is recorded. All steps are repeated three times to obtain statistically accurate results.

\section{Results and Discussion}

During the test phase, the ambient temperature is measured in different methods and double checked to ensure that the sensor and system operate properly and consistently. In order to ensure the system has taken correct measurements or not, the measurement stability was controlled with a calibrated thermometer at regular intervals.

Fig.4 presents the relationship between ambient temperature change and period for visually detection of cold vapor. As it is shown as the temperature increases the vapor speed decreases which refers an increase in particle dimensions.

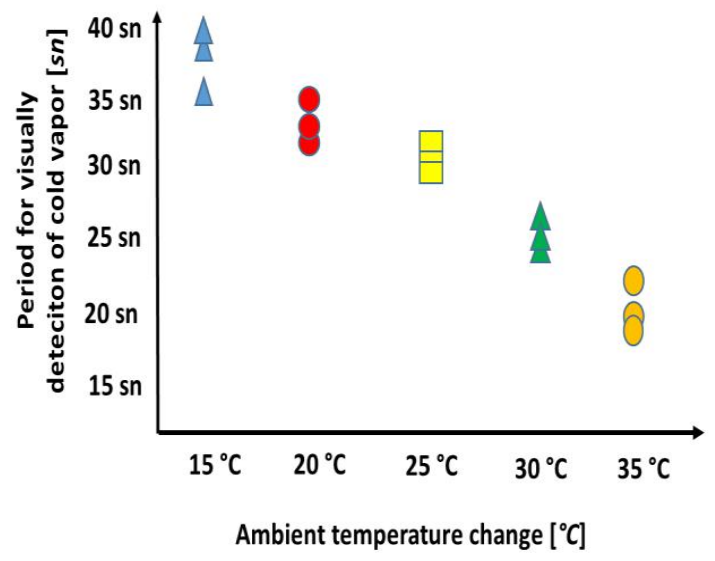

Fig. 4: The relationship between ambient temperature change and period for visually detection of cold vapor.

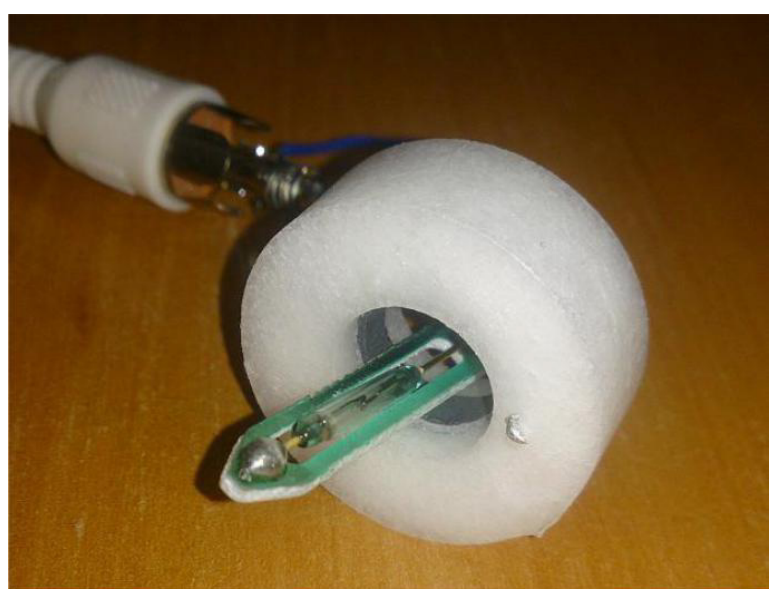

Fig. 5: Level sensor for water measurement

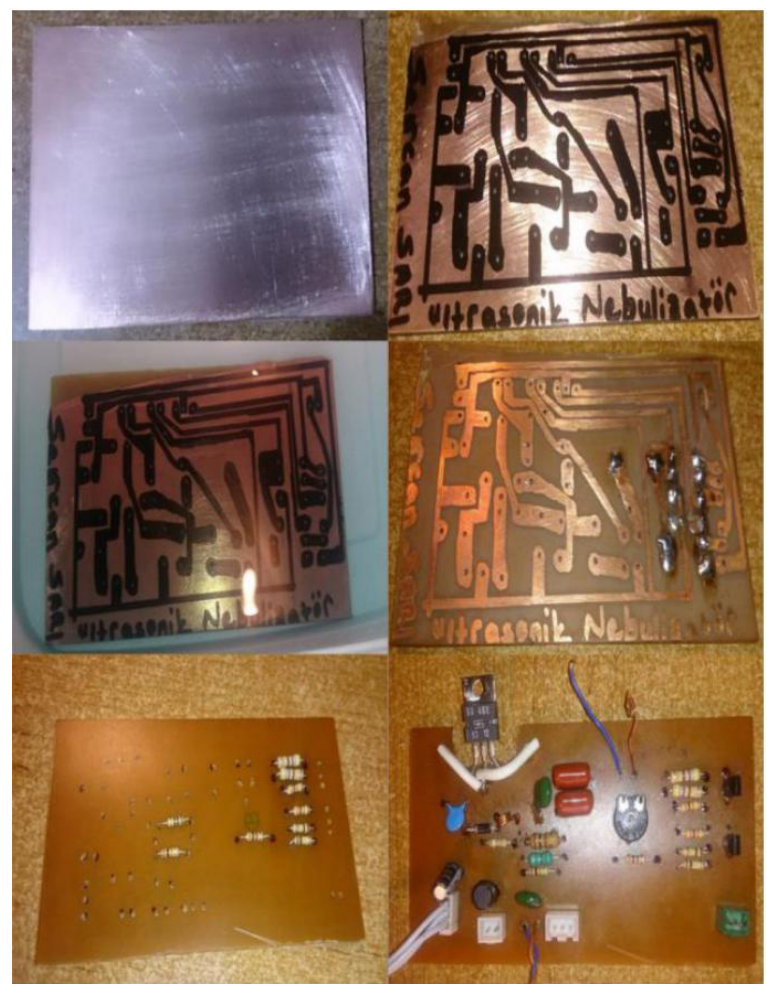

Fig. 6: Designing the circuit board of an ultrasonic nebulizer 

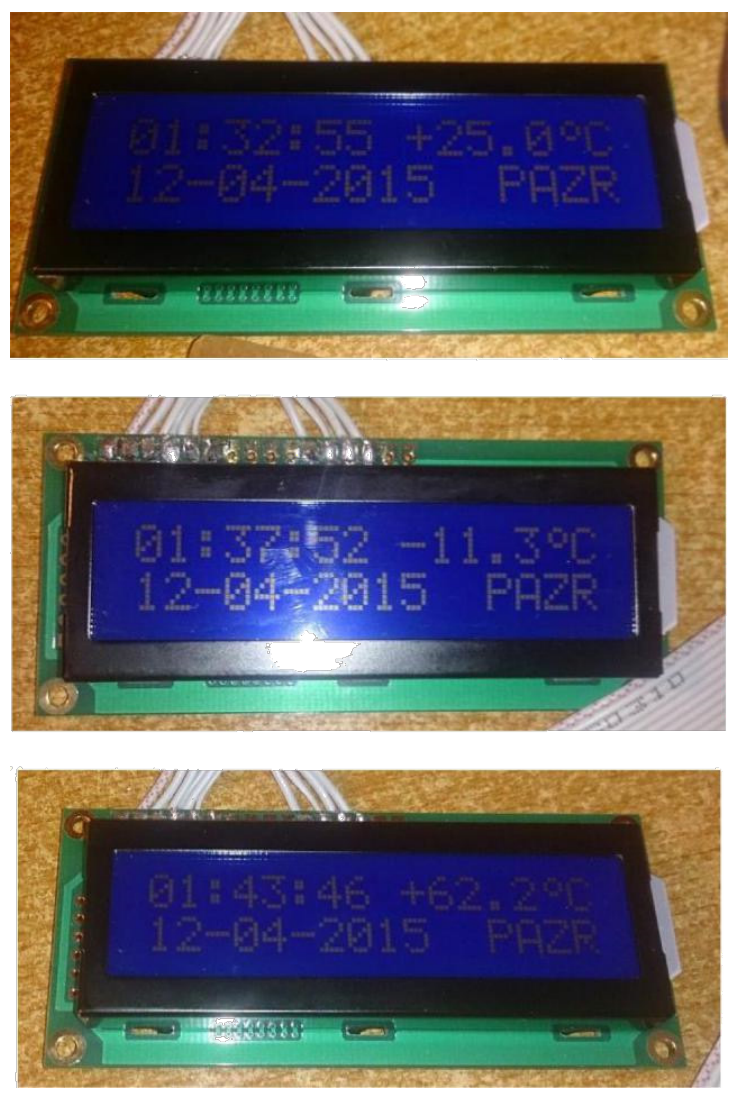

Fig 7: Temperature measurement results a) $25^{\circ} \mathrm{C}$ b) $\left.-11.3^{\circ} \mathrm{C} \mathrm{c}\right)+62.2^{\circ} \mathrm{C}$

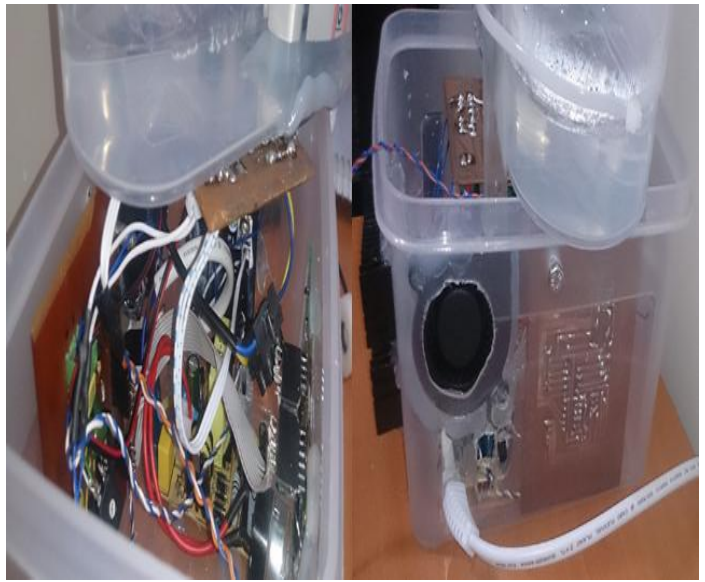

Fig. 8: Inside and back views of the designed ultrasonic nebulizer

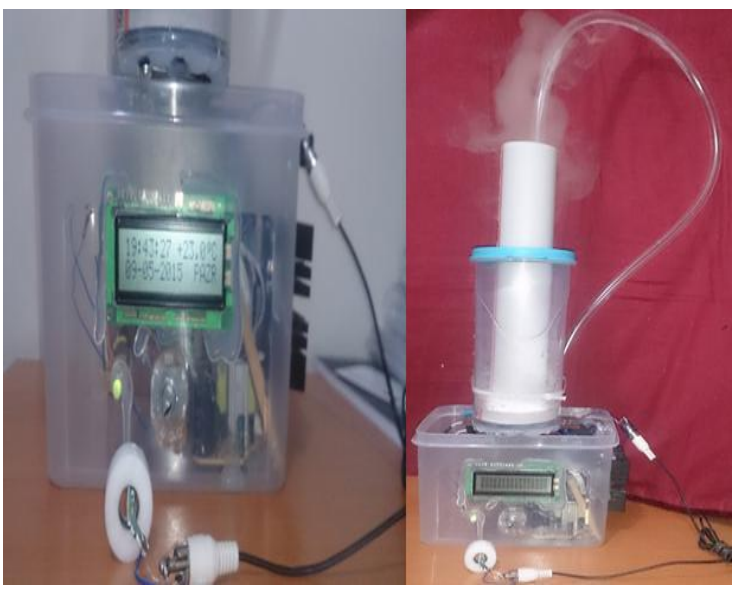

Fig. 9: Final prototype of ultrasonic nebulizer b) During work

\section{Conclusion}

The purpose of this project is to prove that it is quite simple to fabricate home made low cost specially designed ultrasonic nebulizers that is mainly imported to Turkey with high prices.

In addition, it is proved that ambient temperature has serious impact on particle dimensions. It is presented that as the ambient temperature increases five celcius, the speed of cold vapour increases around $10 \%$ which refers a decrease in particle dimensions. As the temperature decreases five celcius, the speed of cold vapor also decreases $10 \%$ which refers an increase in particle dimensions.

As future researches, Particle Image Velocimetry (PIV) might be used to understand the particle dimensions in detail. A PIV may assist us to truly analysis the particle speed and dimensions of the cold vapor as the temperature increases or decreases. Also, in future the sensitivity of the research might be increased, therefore change in particle dimensions and particle speed per one celcius temperature variation might be detected. This may help us to optimize the period for therapeutics.

The most important innovation in this study is to merge a temperature sensor just outside the cover of the ultrasonic nebulizer. This assists users to estimate the particle dimensions and predict the optimum time for therapeutic.

In future, an ultrasonic nebulizer that adjusts the vibration frequency of the ultrasonic crystal based on the change in ambient temperature might be designed. This design may optimize the dimensions of particles and fix the period for therapeutic. This version of an ultrasonic nebulizer will prevent the fluctiations caused by temperature variations of the environment.

This model of an ultrasonic nebulizer is yet haven't fabricated. This should be considered as a future direction.

\section{Conflict of Interest}

The authors declare no conflict of interest.

\section{References}

[1] This paper is an extension of work originally presented in 2016 national Conference on Electrical, Electronics and Biomedical Enginering (ELECO) under the name of

"Ortam Sicakliginin Ultrasonik Nebülizatörler Üzerindeki Etkinliğini Ölçen Sistem Tasarimi”

[2] Ulus B. Et al, Sağlık çalışanları nebülizatörle tedaviyi biliyor mu?, Çocuk Sağlığı ve Hastalıkları Dergisi 2007; 50: 174-179

[3] Güngör S. Et al, Doktorlar, Hemşireler ve Hastalar Nebülizatör Cihazlarını Ne Kadar Doğru Kullanıyor?, Solunum Dergisi t Solunum 2012; 14(3):136140

[4] Muers MF. Overview of nebulizer treatment. Thorax 1997; 52: 25-30

[5] Uçgun İ., Ventilatördeki Hastada Aerosol Tedavisi, Yoğun Bakım Dergisi 2008;8(3):103-110

[6] Hess DR, Nebulizers: Principles and Performance, Respiratory Care June 2000 Vol 45 No 6

[7] Turner MO, Gafni A, Swan D, FitzGerald JM. A review and economic evaluation of bronchodilator delivery methods in hospitalized patients. Arch Intern Med 1996;156(18):2113-2118.

[8] Cates CJ. Holding chambers versus nebulizers for beta-agonist treatment of acute asthma. The Cochrane Database or Systematic Reviews, 1999.

[9] Smye SW, Jollie MI, Littlewood JM. A mathematical model of some aspects of jet nebuliser performance. Clin Phys Physiol Meas 1991;12(3):289-300. 
[10] Nerbrink O, Dahlback M, Hansson HC. Why do medical nebulizers difffer in their output and particle size characteristics? J Aerosol Med 1994;7:259276.

[11] Newman SP. Aerosol generators and delivery systems. Respir Care 1991;36(9):939-951

[12] Larsen KR, Svendsen UG, Molgaard F, Petersen BN. Comparability of albuterol delivered by a piezoelectric device versus metereddose inhaler in patients with chronic obstructive airways disease. J Aerosol Med 1998;11(2):81-88

[13] AARC Clinical Practice Guideline. Selection of aerosol delivery device. American Association for Respiratory Care. Respir Care 1992;37(8):891897.

[14] Bulut S et al, A new algorithm for segmentation and fracture detection in Xray images, Medical Technologies National Conference, 2015, doi: 10.1109/TIPTEKNO.2015.7374572

[15] Çiftçioğlu Ç., Koçak O.Akpek, A., Remote control of centrifuge and injection systems via MATLAB and ARDUINO, Medical Technologies National Conference, 2015, DOI: 10.1109/TIPTEKNO.2015.7374570

[16] Ahmet Öztarhan, Ali Akpek, Efim Oks, Alexey Nikolaev, Modifying medical textiles with antibacterial and friction resistance abilities by an alternative nanotextile technology called ion implantation technique, 15th National Biomedical Engineering Meeting, 2010, 10.1109/BIYOMUT.2010.5479859

[17] Semih Ahmet Cebeci, Çağlar Çiftçioğlu, Onur Koçak,Ali Akpek, Medical Technologies National Conference, 2015, 10.1109/TIPTEKNO.2015.7374571

[18] Ali Akpek, Chongho Youn, Toshiharu Kagawa, Temperature measurement control problem of vibrational viscometers considering heat generation and heat transfer effect of oscillators, 9th Asian Control Conference, 2013, 10.1109/ASCC.2013.6606100

[19] Ucar T., Kocak O., Akpek A., New concept design of an insulin pen for visually impaired or blind diabetius mellitus patients, 2017, 10.1109/TIPTEKNO.2016.7863074

[20] Nikolaev, A. G., et al. "Modification of anti-bacterial surface properties of textile polymers by vacuum arc ion source implantation." Applied Surface Science 310 (2014): 51-55, doi.org/10.1016/j.apsusc.2014.04.002

[21] Akpek, Ali, et al. "Effect of thermal convection on viscosity measurement in vibrational viscometer." Journal of Flow Control, Measurement \& Visualization 2014 (2014), 10.4236/jfcmv.2014.21003

[22] Akpek, Ali. "Effect of non-uniform temperature field in viscosity measurement." Journal of Visualization 19.2 (2016): 291-299. doi:10.1007/s12650-015-0311-0

[23] Akpek Ali, Youn Chongho and Kagawa Toshiharu "A study on vibrational viscometers considering temperature distribution effect." 日本フルードパ ワーシステム学会論文集 45.3 (2014): 29-36. doi.org/10.5739/jfps.45.29 